\title{
Mapping the Trend of Humor Studies in Educational Arena: A Text- analytic Approach
}

\author{
Fatih ERDOĞDU* \\ Computer Technology, Zonguldak Bülent Ecevit University, Zonguldak, Turkey \\ ORCID: 0000-0003-1022-8570
}

Article history

Received:

15.09.2021

Received in revised form: 10.11.2021

Accepted:

23.11.2021

Key words:

Humor,

Text mining,

Concept mapping trend,

Education
Humor is considered an educational method that can be implemented in educational processes with a wide range of educational variables. Examining the scope of research on educational humor has the potential to guide future studies. Therefore, the aim of this study is to show the conceptual trend in humor research in education over the past decade. 989 publications on the subject of humor in education were analyzed using the text mining method. A text analytic tool was used for the analysis, and the titles, abstracts, and keywords were included in the text analytics. As a result of the study, humor was studied in terms of various variables in different educational fields. In addition, the reflections of humor in education base on technological developments and the target groups applied were also revealed. The findings revealed the conceptual relationships and concept maps by year. It was concluded that the concept of humor in educational research is particularly related to the variables of motivation, attention, skill, creativity, engagement, and interest. Upon comparing 2010 and 2019, it has been observed that concepts related to online education, science, collaborative learning, and technology in humor studies have spread in recent years. In addition, humor has also emerged as a research phenomenon in language, health, and science education.

\section{Introduction}

Humor, which exists in all cultures and possesses almost all individuals, is a universal phenomenon that relates to all aspects of human life, relationships, and interactions (Carrell, 2008). It is not just about jokes, laughter, and fun, but has a variety of positive effects in many areas if used consciously. Typical studies on humor are usually based on the frameworks of language, philosophy, psychology, and anthropology (Guo \& Wang, 2017; Wu et al., 2009). In addition to these framework conditions, communication and educational areas should also be mentioned. The literature focuses on the artistic side of humor, psychology on the emotional side to make people laugh, sociology on its social side, and lately management has tried to treat humor as a management aspect and pedagogy as an educational tool (Sahin, 2018). Nowadays, an increasing number of scholars have focused on the cognitive and neural dimension of humor, and it is gradually becoming an interdisciplinary field (Guo \& Wang, 2017). The definitions of humor, which is studied in interdisciplinary fields, also vary. Still, many scholars agree that humor involves communicating several inappropriate meanings that

\footnotetext{
*Correspondency: fatih.erdogdu@beun.edu.tr or fatiherdogdu67@gmail.com
} 
are entertaining (Martin \& Ford, 2018). Ruch and Hofman (2017) stated that humor is now often used as an umbrella term for all forms of comics / funny. In another definition, Martin \& Lefcourt (2004) claimed that humor is a cognitive continuum that includes emotional elements. These definitions of humor may shift depending on the area in which humor is implemented, the perspective on humor, the theoretical basis of humor, and the focus of humor. Thanks to this variability, humor, which has developed into an interdisciplinary structure, is preferred by educators, particularly because of its many advantages in the educational field. Educators from various academic fields have long paid attention to the potential of humor in education (Neff \& Rucynski, 2017). As part of the potential, educational dimensions of humor, its effect, and its relationship with various variables in educational humor studies are examined, so it is remarkable to show the trends in humor studies in education by year.

Humor provides a way to manage life by reducing negative impact and stress from threats (Chang et al., 2014). This trait shows that it can bring about mental well-being. In terms of the psychological and cognitive effects of humor, it improves mental health, motivation, the selfregulatory process, memory, and attention (Pekrun \& Perry, 2014). In addition, it also has positive physiological effects such as increasing the oxygen content in the blood, releasing endorphins, reducing the stress hormone, and improving mental health (Andarab, 2019; Tsukawaki et al., 2020). Humor has positive effects in the social and communicative sense as well as in its psychological, cognitive and physiological effects. Strong interpersonal relationships and communication, social skills, positive interaction and increasing group cohesion are the most important positive effects. (Banas et al., 2011; Lefcourt, 2001). It is possible to see all of these positive psychological, physiological, cognitive, affective and social effects, directly or indirectly, in learning processes, so uncovering the concepts associated with humor can reveal the function of humor, its scope and trends in education. This situation can guide researchers willing to do research on humor in education.

\section{Humor in Education}

Research on educational humor began to be widespread in the late 20th century (Tsukawaki et al., 2020). While the scope of these studies provides a general framework for the concept of humor in education, it also provides a deeper framework for the relationship between humor and other educational variables. How humor plays an educational role and how it brings educational benefits has become the basic topic of humor research. The purpose of using humor in education is to increase the quality of education, as with any other educational method and technique. In this context, the benefits of humor for learning from a teacher's perspective can be listed as follows: 

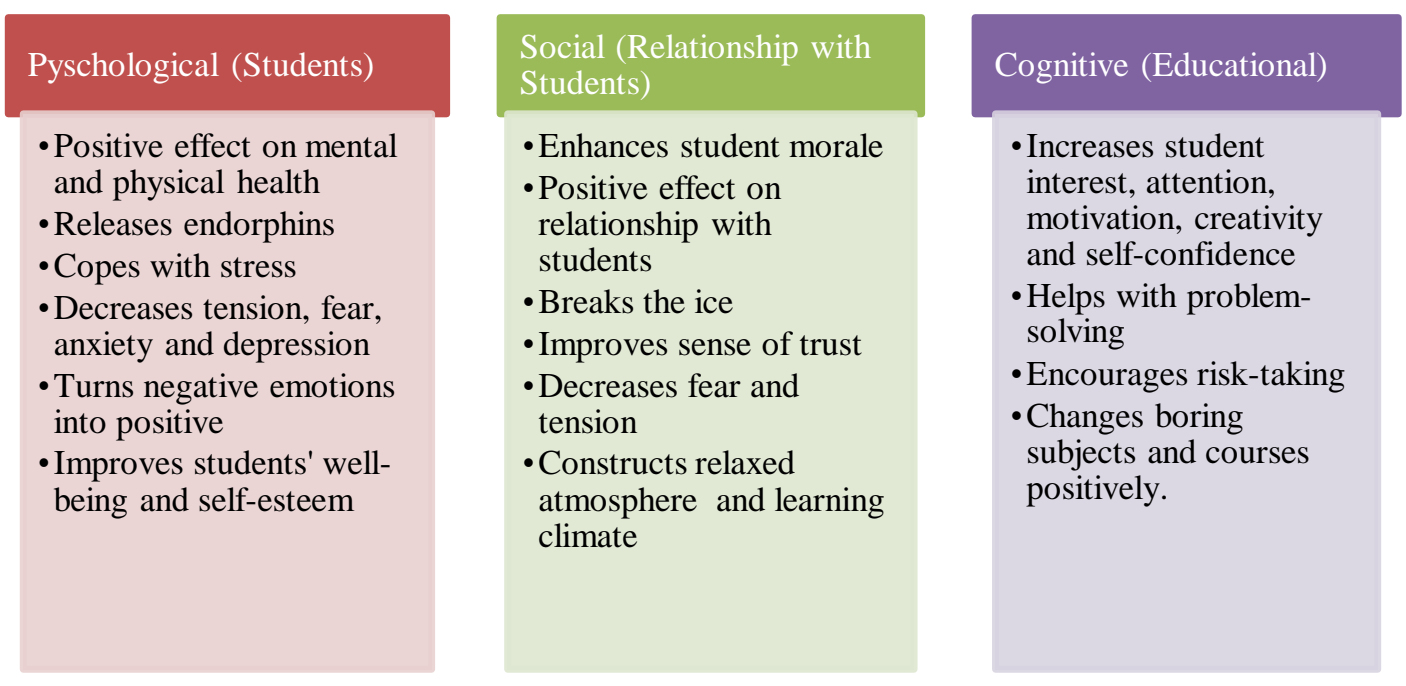

Figure 1. Benefits of humor in learning from instructors' perspectives (Lei et al., 2010, p. 327)

Figure 1 shows the psychological, social and cognitive potential of humor in the learning process in the context of general education. When the benefit is examined, humor turns out to be a tool for learning processes to achieve the desired level of a high-quality educational context. The purpose of instruction design is to help people learn easier and better (Reigeluth, 2013), so it is important how and for what purpose humor should be used and assessed in the learning process in order to achieve the desired level of education.

Humor as a pedagogical tool is defined as "walking on a tightrope" and, if done well, it has the potential to enhance learning by making learning a pleasure (Poirier \& Wilhelm, 2014). In addition to its psychological, social, and physical benefits, if not properly implemented, it can have a negative impact on learners. It can distract students in class, reduce their motivation to teach and thus hinder learning (Poirier \& Wilhelm, 2014). When used correctly, humor has the potential to increase self-esteem, self-motivation, and engagement in the learning process by creating a positive learning environment (Garner, 2006). Moreover, humor is a powerful tool as an icebreaker for relationships with students and teachers. The number of the educational benefits of humor can be increased such as positive effects on attention, attitude, and higher-order thinking skills (Rule \& Auge, 2005). Moreover, humor creates a positive relationship with students in the classroom (de la Rosa, 2005). Strategies for the use of humor in educational processes are also developed. Hellman (2007) suggested seven simple steps for teachers to use humor in the classroom: (1) be yourself, (2) pick your spots, (3) be politically correct, (4) know your audience, (5) use Oxymoron, alliteration, and acronyms, (6) sometimes, you need to be quiet and (7) recognize others' humor. In addition, Berk (1996) proposed various strategies as follows:

- Low-risk humor techniques should be preferred to enhance learning and student performance.

- Humorous strategies need to be planned well and systematically.

- Humorous materials and contents should be designed with the characteristics of each class in mind.

- Using humor that appeals to two or more senses, including the visual and auditory, can be more effective.

- The use of offensive humor should be avoided (Berk, 1996). 
Given the humor effects mentioned above, it is noteworthy that it creates a suitable environment for improving learning. Another notable issue is that humor has an impact on variables related to learning. At this point it is important to establish the conceptual relationship with the variables to determine the future direction of humor research in education. In this way the concept of educational humor can be mapped, and the general framework can be drawn. In addition, new fields of research on educational humor can be opened up by showing the trend in humor research.

\section{The Present Study}

For the present study, we examined humor publications in education using textanalytical methods for emerging conceptual trends in educational humor in the last decade. The concept of humor is a topic that is investigated in different areas of education with different variables and with different research methods. Here, uncovering the relationship of the concept of humor to others in education can discover the trend towards humor in education. One of the most effective methods for doing this is to create concept maps using the text mining method. Leximancer as a text mining tool automatically analyzes text documents, creates concepts and creates models and graphics. The tool offers the opportunity to research the improvement of scientific discipline by comparing conceptual trends from studies (Nunez-Mir et al., 2015). Nowadays it is possible to find a lot of information in text format in digital media. Since the masses of information have to be analyzed and interpreted, this is where the text mining method comes into play (Delgado et al., 2000). Text mining is an automated process for extracting meaningful information from large data sets of text. (Khan \& Ghosh, 2020). Text mining, a valid method, was preferred to manual analysis because of the mass of humor studies in education. In this context, the direction of the studies of humor and the relationship to which concepts have been revealed through the illustration of the conceptual relationships are shown. The aim of the study is to show the conceptual trend of humor studies in education over the past decade. To this end, the research questions are as follows:

(1) What are the bibliometric of humor publications in education?

(2) What are the annual trends of educational humor publications?

\section{Method}

\section{Research Process}

This study, based on the text analytic approach, comprises three basic phases: determination of the digital database, decision on search string and scan coverage, processing, and transmission of the data to text mining tools for analysis.

\section{Determination of the Digital Database}

As a digital database, Web of Science (WoS) was preferred because of its wide coverage and high-quality publications. It provides titles, abstracts, and keywords in a clean and parsable format for text analysis. The database is an effective and efficient instrument for interdisciplinary recording and for comparing studies in different fields of science (Archambault et al., 2006). 


\section{Decision on Search String and Scan Coverage}

The digital database presents large scale bibliometric research as publication type, authors, countries, indexes, and institutional addresses. In the next step, primary and secondary search strings in the advanced search, document type, language and citation index were determined for the data collection.

\section{Preparation and Transmission of Data for Text Mining}

Finally, the titles, abstracts and keywords of all publications are downloaded in text format. Prior to analysis, publications were examined in terms of the reach of humor in education. Publications outside the scope have been removed. At this stage, all uppercase letters are also converted to lowercase and the punctuation marks have been removed for analysis. After the concept map analysis, the data was interpreted by year in the context of humor in education by two researchers in the field of text mining and humorous learning.

\section{Data Collection}

The scope of the search was initially determined when the data was collected. The following search string was created with the advanced search option in the WoS database:

Table 1. Search string

\begin{tabular}{ll}
\hline Search String & Meaning \\
\hline (TS=( ( "humor" OR "humor" OR "humorous" ) AND ( & The primary string must include any of humor, \\
"learning" OR "instruction" OR "education" OR & $\begin{array}{l}\text { humor and humorous. } \\
\text { "training" OR " teaching") ) }\end{array}$ \\
& $\begin{array}{l}\text { With the primary string, secondary string must } \\
\text { include any of learning, instruction, education, } \\
\text { training, and teaching. }\end{array}$ \\
\hline
\end{tabular}

\section{TS: topic}

In addition to the search term used in the subject areas by year, the search was carried out by selecting the criteria in Table 2. The titles, abstracts, and keywords of the related publications from the WoS digital database were drawn within the framework of the following criteria:

Table 2. Search criteria of WoS

\begin{tabular}{|c|c|c|c|c|}
\hline Document Type & Language & Timespan & Citation Index & Total \\
\hline $\begin{array}{l}\text { article, proceeding, } \\
\text { book chapter, editorial } \\
\text { material, early access, } \\
\text { meeting rabstract, } \\
\text { letter, biographical } \\
\text { item }\end{array}$ & English & 2010-2019 & $\begin{array}{l}\text { Science Citation Index Expanded } \\
\text { Social Sciences Citation Index } \\
\text { Arts \& Humanities Citation Index } \\
\text { Conference Proceedings Citation Index } \\
\text { Conference Proceedings Citation Index- } \\
\text { Social Science \& Humanities } \\
\text { Book Citation Index-Science } \\
\text { Book Citation Index- Social Sciences \& } \\
\text { Humanities } \\
\text { Emerging Sources Citation Index }\end{array}$ & 1014 \\
\hline
\end{tabular}

The resulting 1014 publications were examined for humor and education. As a result of the review, 25 publications were excluded because they had no relation to the educational dimension of humor. The term humor was used in a different sense in medicine like "aqueous humor the fluid produced in the eye" and was therefore excluded from analysis. A total of 989 publications were included in the analysis because they were eligible for the scope. 


\section{Data Analysis Tools}

The text mining analysis tool called Leximancer automatically analyzes text documents to identify, define and classify the concepts and visually represent emerging concepts with relevance to one another. With this tool, the classified concepts are first determined, then the group of words that form a term is compiled and the literature is classified according to the identified and defined concepts (NunezMir et al., 2016). After the three-step analysis process is complete, a user can visually view the concept map, generate reports, and rank the relationship rates between the concepts. Grech et al. (2002) performed separate manual and automated content analyzes to test the validity of the Leximancer software, and as a result, it was found that the percentages of analysis were almost equal and confirmed the validity. To prepare the text document for analysis, all text has been converted to lower case and punctuation marks have been removed. Later, most of the same words and singular-plural forms that emerged from the analysis in the Leximancer software were combined. In addition, the words' purpose and aim, which appear frequently in the summaries of the studies, are not included in the analysis. Figure 2 shows how Leximancer processes text documents.

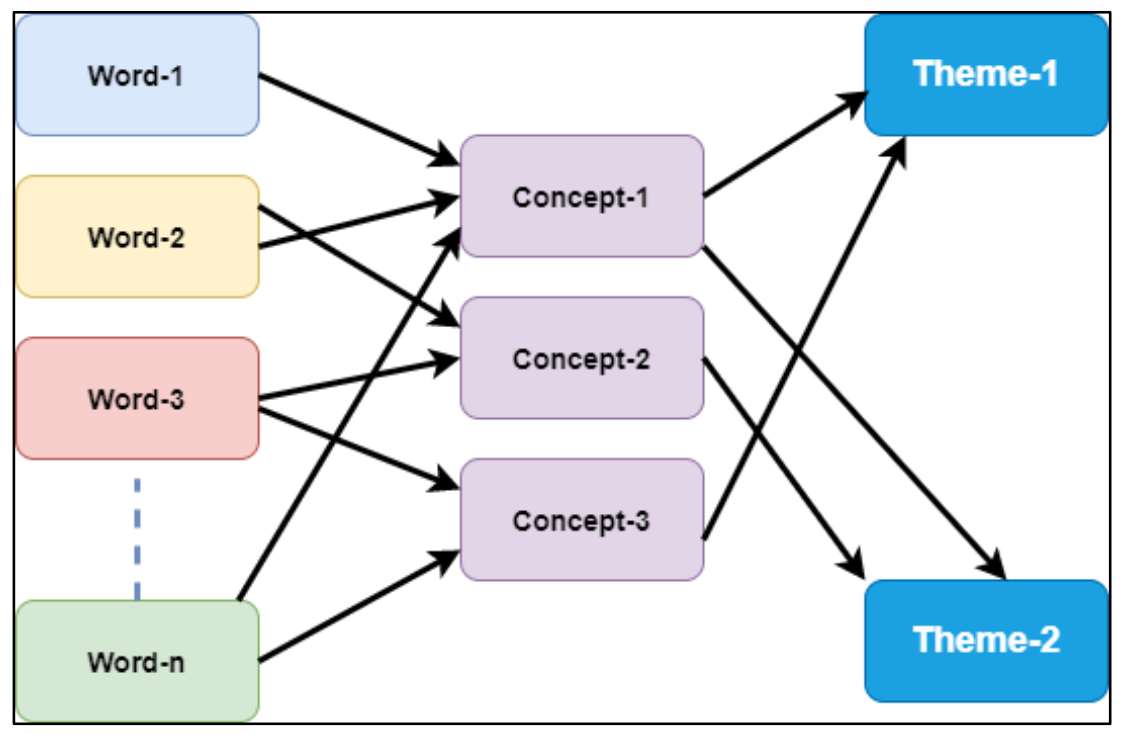

Figure 2. A model of how Leximancer handles text documents processes (Hyndman \& Pill, 2018)

\section{Results}

\section{Bibliometric of the Humor Publications in Education}

In this section, publication time trends, publication types, and top 10 prolific countries are given, respectively.

\section{Publication Time Trends}

Figure 2 indicates the number of publications on humor in education by year from 2010-2019 in the Web of Science database. From 2010 to 2013 the publications escalated from 46 to 62. From 2012 to 2013 and from 2016 to 2017 there was a slight decrease in the number of publications. 


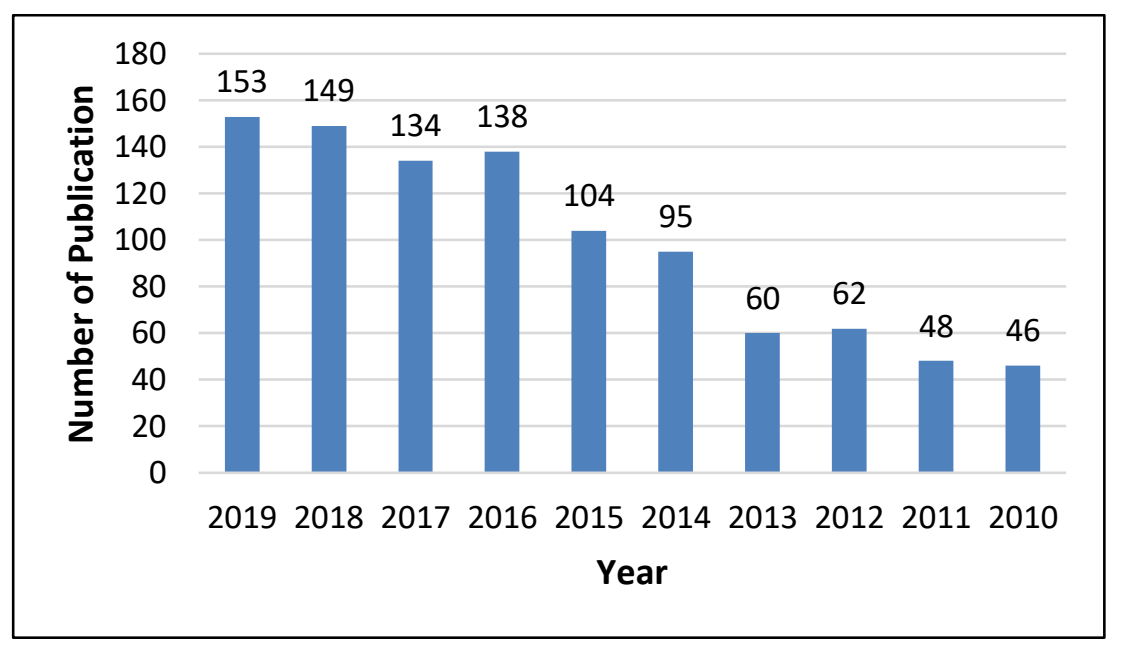

Figure 3. Publication time trends from 2010-2019

The number of publications increased by $61 \%$ from 2014 to 2019. It is also noteworthy that most of the publications were produced in 2018 and 2019. The increase in the publications from 2010 to 2019 is $232.6 \%$ (escalation from 46 to 153). Compared to the number of publications between 2010 and 2015, there was an explosion of publications after 2015 .

\section{Publication Types}

The top four publication types of humor in education were the article $(76.23 \%)$, the proceeding paper (17.49\%), the book chapter (4.04\%), and the others $(2.22 \%)$.

Table 3. Publication types of humor in education

\begin{tabular}{lll}
\hline Publication Types & The Number of Publication & The \% of Publication \\
\hline Article & 754 & $76.23 \%$ \\
Proceedings Paper & 173 & $17.49 \%$ \\
Book Chapter & 40 & $4.04 \%$ \\
Others & 22 & $2.22 \%$ \\
\hline
\end{tabular}

*Others: editorial material, early access, meeting abstract, letter, biographical item.

Table 3 shows that the articles represent many of the publication types $(n=754)$. The second largest publication type is the Proceeding Paper $(n=173)$.

\section{Top 10 Prolific Countries}

Figure 3 shows the top prolific countries for humor research in education. Half of the studies $(n=392)$ were carried out at universities in the USA. The rest was done in Europe, Australia, Canada, and China. 


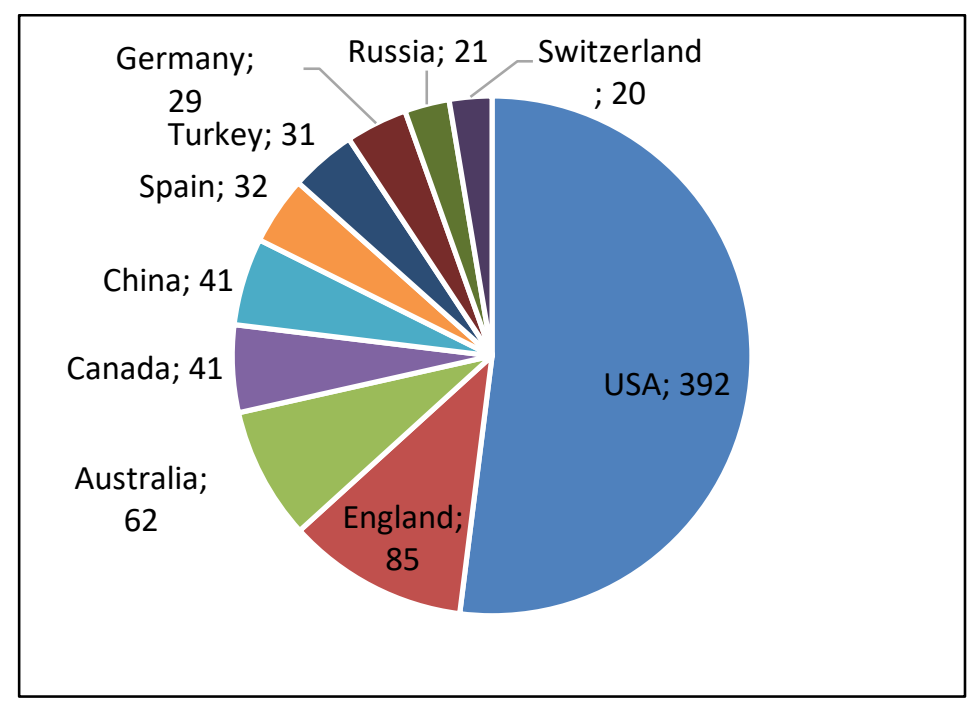

Figure 4. Countries that produce the most humorous publications in education

\section{Concept Mapping Trends of Humor Research in Education}

\section{Concept Mapping for the Year 2010}

The concept map was created using a text analysis tool to analyze the titles, abstracts and keywords of 47 studies in 2010. It includes a connectivity score to indicate the following hit themes: students (100\% connectivity), followed by humor ( $85 \%$ connectivity), education (26\%), work (19\%), training (16\%), time (13\%) and innovation (7\%). The first three themes are an expected outcome in terms of the research context. In addition, these hit themes contain diverse connected concepts.

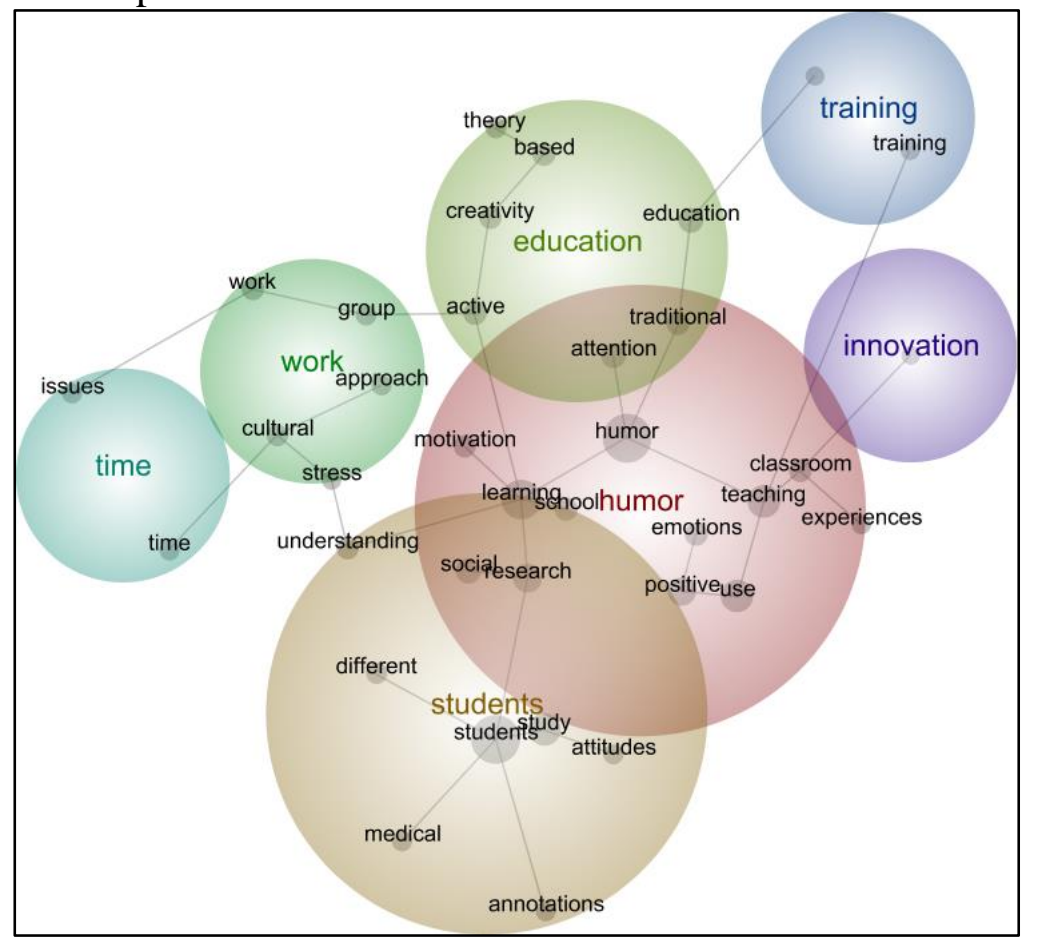

Figure 5. Overall concept map of the publications in 2010 
The humor theme notably encompasses classroom, motivation, attention, and social concepts. Classroom and teaching concepts combine the topic of innovation and humor topics in an interesting way. This is a trace of the existence of humor as a novel approach in the classroom. In another major topic, the student and medical concepts show the field of education in which humor is applied, and the attitude concept shows the dependent variable in which the effect of humor is measured. The fact that the training topic is also a hit theme may indicate that humor was used as an educational tool as a part of training. When the concepts in other major topics are examined, it goes without saying that the effect of humor on creativity and stress has been examined and is based on theory and culture.

Table 4 shows the relationship of the concepts in the 2010 publications on humor. The social (20\% relevance), training (16\% relevance), attention (15\%), classroom (\%15), cultural (14\%), group (14\%), school (13\%), emotions (13\%), medical (13\%), motivation (12\%), creativity (10\%), attitudes (10\%), stress $(8 \%)$ and innovation $(7 \%)$ concepts determine the scope of humor research in education in order to reveal the conceptual trend of this year's humor studies in education.

Table 4. Ranked lists of the concepts associated with humor in 2010

\begin{tabular}{|c|c|c|c|c|c|}
\hline Concept & Relevance $(\%)$ & Bar Chart & Concept & Relevance $(\%)$ & Bar Chart \\
\hline students & 100 & & active & 13 & \\
\hline humor & 85 & 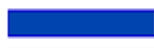 & school & 13 & \\
\hline learning & 47 & & emotions & 13 & \\
\hline teaching & 40 & & understanding & 13 & \\
\hline study & 38 & & medical & 13 & \\
\hline use & 38 & & time & 13 & \\
\hline positive & 30 & & issues & 13 & \\
\hline research & 27 & & motivation & 12 & \\
\hline education & 26 & & annotations & 12 & \\
\hline social & 20 & & creativity & 10 & \\
\hline work & 19 & L & approach & 10 & \\
\hline training & 16 & L & attitudes & 10 & \\
\hline attention & 15 & & experiences & 9 & \\
\hline based & 15 & 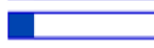 & higher & 9 & \\
\hline classroom & 15 & 工 & stress & 8 & $\pi$ \\
\hline traditional & 14 & & innovation & 7 & \\
\hline cultural & 14 & & & & \\
\hline theory & 14 & & & & \\
\hline different & 14 & & & & \\
\hline group & 14 & 工 & & & \\
\hline
\end{tabular}

Concept Mapping for the Year 2011

The first four main topics are humor (100\% connectivity), students (92\% connectivity), language (35\%) and learning (30\%). This concept map created from 48 publications shows the important concepts that enable the hit themes to interact with one another. In contrast to the concept map from 2010, language and elements concepts have emerged as interpretable hit themes. The highlight of the language theme shows that language education studies have increased this year. The fact that the elements concept is a hit can be interpreted in such a way that the humorous elements were used as content in the classroom environment. 


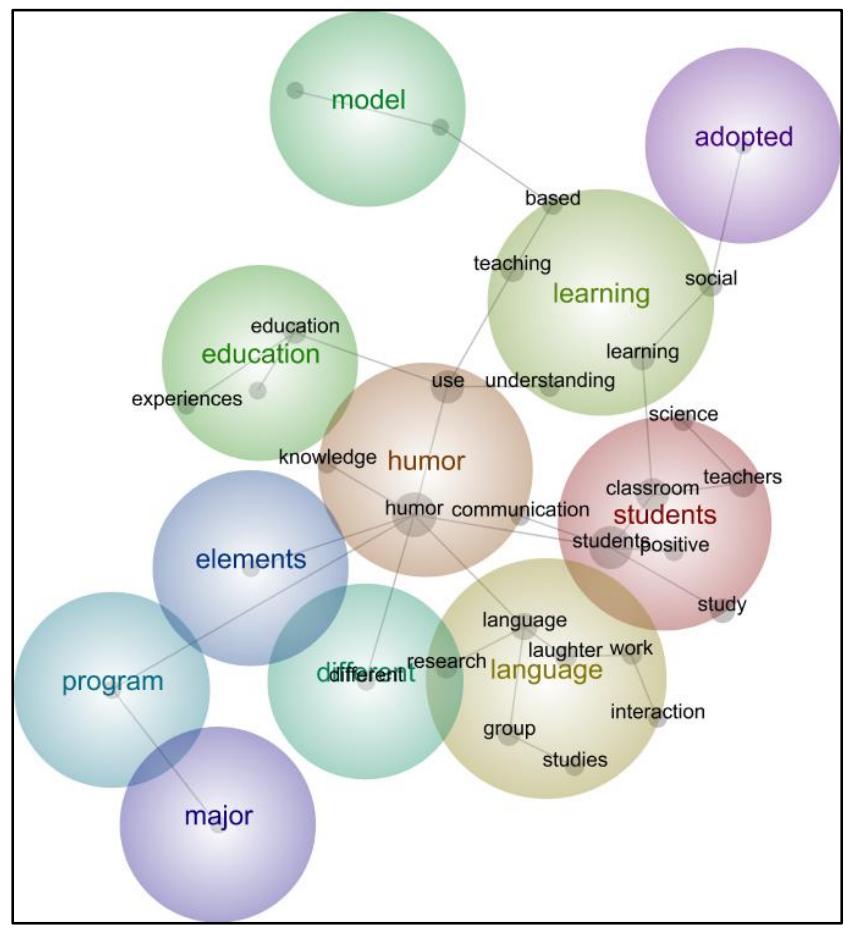

Figure 6. Overall concept map of the publications in 2011

The major themes include diverse and related concepts as the follows: classroom (46\% relevance), language (35\% relevance), teaching (\%35 relevance), teachers (\%32 relevance), social $(28 \%)$, laughter $(19 \%)$, science $(15 \%)$, communication $(14 \%)$, interaction $(11 \%)$ and model (\%9 relevance). These concepts can show that humorous elements have been implemented by teachers to enable interaction in the classroom in the fields of science, communication, language and social. Table 5 indicates ranked lists of all concepts related to humor in 2011. With the difference of the 2010 publications, training and medical concepts were not encountered. Instead of these concepts, language and science concepts were highlighted in the 2011 publications.

Table 5. Ranked lists of the concepts associated with humor in 2011

\begin{tabular}{|c|c|c|c|c|c|}
\hline Concept & Relevance (\%) & Bar Chart & Concept & Relevance (\%) & Bar Chart \\
\hline humor & 100 & & work & 15 & \\
\hline students & 92 & & understanding & 15 & \\
\hline use & 55 & & positive & 15 & \\
\hline classroom & 46 & & studies & 15 & \\
\hline language & 35 & & program & 15 & \\
\hline teaching & 35 & & knowledge & 14 & \\
\hline teachers & 32 & & communication & 14 & \\
\hline study & 31 & & experiences & 14 & \\
\hline learning & 30 & & different & 12 & \\
\hline social & 28 & & major & 12 & 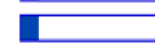 \\
\hline education & 27 & & adopted & 12 & 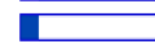 \\
\hline group & 22 & & interaction & 11 & 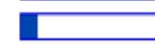 \\
\hline research & 20 & I & elements & 11 & \\
\hline laughter & 19 & I & people & 11 & \\
\hline based & 19 & & time & 9 & \\
\hline science & 15 & 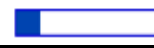 & model & 9 & \\
\hline
\end{tabular}


Concept Mapping for the Year 2012

The concept map of humor in education from 2012, obtained from 62 publications, includes major and meaningful themes as the follows: use (90\% connectivity), humor (100\% connectivity), learning (82\% connectivity), students (64\% connectivity), personal (19\% connectivity), training (26\% connectivity), and cartoons (16\% connectivity). Unlike 2010 and 2011, the cartoons and personal themes are standout this year. This can indicate personal learning and cartoons in humor studies.

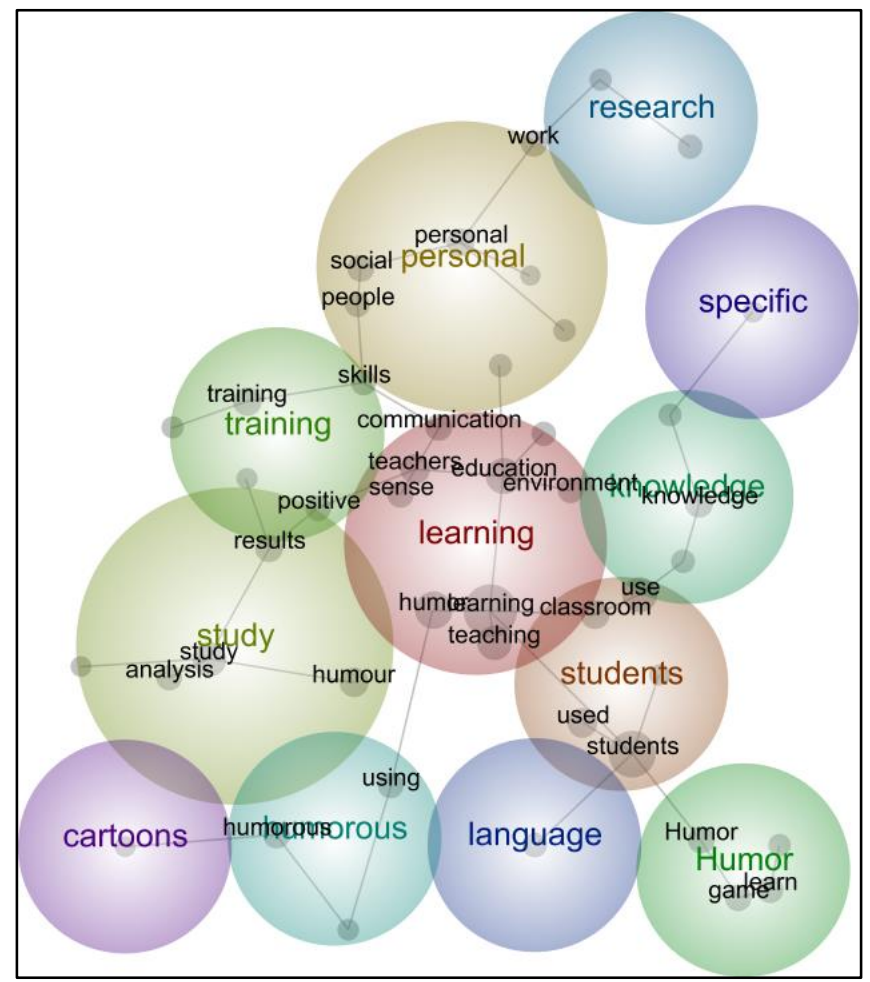

Figure 7. Overall concept map of the publications in the year 2012

Examining the concepts under the hit themes in Figure 6, it is noticeable that there are different concepts from previous years. The most striking concepts are as follows: cartoons (16\% relevance), game (18\% relevance), video (13\% relevance), sense (14\%) and life (12\%). It was also found that the relevance rate of the training (\%26) concept increased more than in previous years. Table 6 shows the ranked lists of the concepts associated with humor in 2012. 
Table 6. Ranked lists of the concepts associated with humor in 2012

\begin{tabular}{|c|c|c|c|c|c|}
\hline Concept & Relevance (\%) & Bar Chart & Concept & Relevance (\%) & Bar Chart \\
\hline humor & 100 & & game & 18 & \\
\hline use & 90 & & communication & 16 & \\
\hline learning & 82 & & skills & 16 & \\
\hline students & 64 & & positive & 16 & \\
\hline education & 49 & & environment & 16 & \\
\hline study & 43 & & educator & 16 & \\
\hline teaching & 35 & & cartoons & 16 & \\
\hline training & 26 & & sense & 14 & \\
\hline social & 26 & & context & 14 & \\
\hline knowledge & 25 & & participants & 14 & \\
\hline analysis & 25 & & time & 14 & \\
\hline work & 23 & 工 & specific & 14 & \\
\hline research & 23 & & form & 13 & T \\
\hline personal & 19 & L & development & 13 & \\
\hline results & 19 & & video & 13 & $\bar{T}$ \\
\hline language & 19 & & data & 13 & \\
\hline classroom & 18 & & life & 12 & 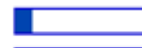 \\
\hline people & 18 & 口 & others & 10 & \\
\hline
\end{tabular}

\section{Concept Mapping for the Year 2013}

The 2013 concept map, generated by analyzing titles, abstracts and keywords from 60 publications from the Web of Science database, consists of 12 hit topics, eight of which (students, teachers, study, humor, learning, course, including and life) are more important and meaningful than others to easily interpret the context of educational humor publications. It includes a relevance score to demonstrate the following hit themes: humor (100\% relevance), followed by students (62\% connectivity), study (56\%), teachers (34\%), learning (33\%), including $(27 \%)$, course $(17 \%)$ and life $(18 \%)$. These hit themes have related concepts that give meaning to the topics.

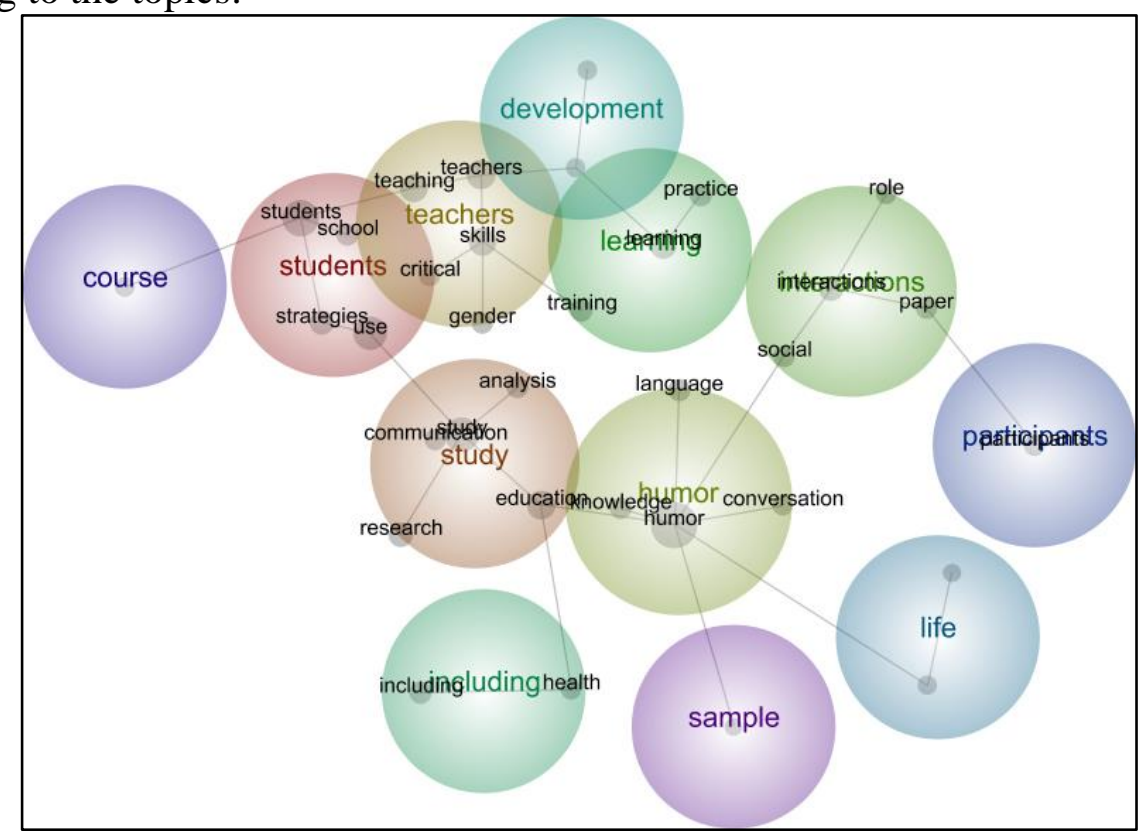

Figure 8. Overall concept map of the publications in the year 2013

The humor theme includes conversation (11\% relevance), knowledge (16\% relevance) and language concepts (15\% relevance). This could be a clue of the use of humor in language 
education. In students theme, school (15\% relevance), strategies (\%22 relevance) and critical (11\% relevance) concepts are prominent. That means the humorous strategies in the school environment. In addition, communication, health, skills, training, interactions, and gender concepts in other themes are noteworthy as they favor humor in educational institutions. All concepts and their rank are listed in Table 7.

Table 7. Ranked lists of the concepts associated with humor in 2013

\begin{tabular}{|c|c|c|c|c|c|}
\hline Concept & Relevance (\%) & Bar Chart & Concept & Relevance $(\%)$ & Bar Chart \\
\hline humor & 100 & & training & 18 & \\
\hline students & 62 & & life & 18 & \\
\hline study & 56 & & role & 17 & \\
\hline use & 49 & & course & 17 & \\
\hline teachers & 34 & & analysis & 16 & \\
\hline education & 34 & & knowledge & 16 & \\
\hline learning & 33 & & language & 15 & \\
\hline skills & 28 & & school & 15 & \\
\hline teaching & 27 & & communication & 15 & \\
\hline research & 27 & & health & 15 & \\
\hline including & 27 & & development & 14 & \\
\hline interactions & 25 & & gender & 12 & \\
\hline strategies & 22 & & based & 12 & \\
\hline participants & 22 & & critical & 11 & \\
\hline practice & 20 & & conversation & 11 & \\
\hline social & 20 & & sample & 10 & \\
\hline paper & 20 & & process & 9 & \\
\hline
\end{tabular}

\section{Concept Mapping for the Year 2014}

A text analysis of the titles, abstracts and keywords of 95 publications resulted in 12 hit themes on the subject of humor. Figure 8 indicates the themes, concepts, and relationships to one another. One of the hit themes is the use term (100\% relevance) consisting of humor, students, language, teaching, approach, research, and analysis concepts. The education theme (44\% relevance) includes communication and media concepts. Other prominent themes are children (\%14 relevance) and elements (12\%). This indicates that humor may be preferred by teachers in child education level and can be used as humorous elements in course contents. In previous years, children and elements themes in particular were not found. 


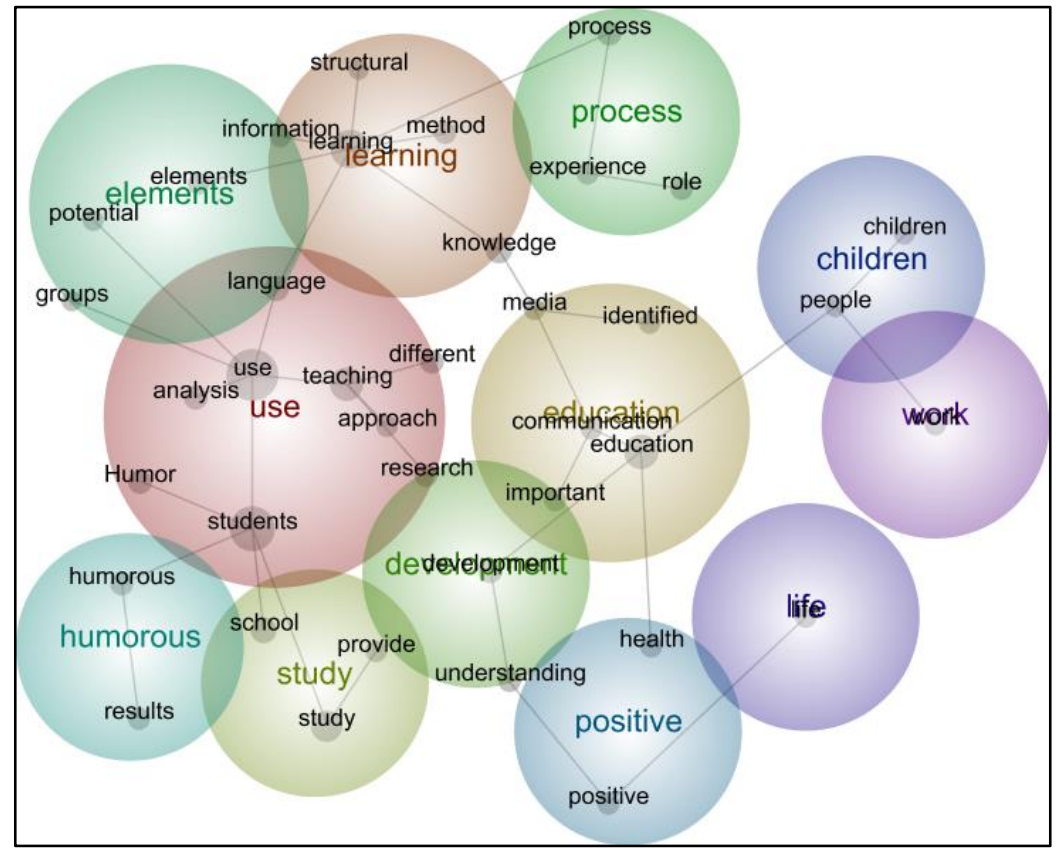

Figure 9. Overall concept map of the publications in the year 2014

Table 8 shows ranked lists of the concepts related to humor in 2014. Some of the prominent concepts and relevance degree are as follows: school (20\%), knowledge (19\%), language (19 $\%)$, role (14\%), children (14\%), experience (12\%), health (12\%) and media (10\%). While the relevance level of the school concept is increasing compared to previous years, the relevance level of the language concept is at the same level. The media concept has emerged for the first time this year.

Table 8. Ranked lists of the concepts associated with humor in 2014

\begin{tabular}{|c|c|c|c|c|c|}
\hline Concept & Relevance (\%) & Bar Chart & Concept & Relevance (\%) & Bar Chart \\
\hline use & 100 & & life & 14 & \\
\hline students & 71 & & children & 14 & \\
\hline learning & 56 & & research & 13 & \\
\hline education & 44 & & experience & 12 & \\
\hline study & 41 & & health & 12 & \\
\hline teaching & 33 & & provide & 12 & \\
\hline school & 20 & & potential & 12 & \\
\hline knowledge & 19 & & method & 12 & \\
\hline language & 19 & L & elements & 12 & \\
\hline process & 19 & & information & 12 & \\
\hline positive & 19 & & important & 11 & \\
\hline understanding & 17 & & identified & 11 & \\
\hline work & 17 & & groups & 11 & \\
\hline different & 17 & & approach & 10 & 口 \\
\hline analysis & 16 & & communication & 10 & 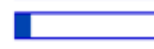 \\
\hline humorous & 16 & & media & 10 & 世 \\
\hline development & 15 & & people & 9 & 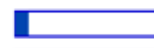 \\
\hline results & 15 & & structural & 7 & $\pi$ \\
\hline role & 14 & & & & \\
\hline
\end{tabular}


Concept Mapping for the Year 2015

The year 2015 concept map acquired from 104 humor publications in education. Analyzing the titles, abstracts, and keywords of the publications, 12 hit themes emerged with related concepts, as shown in Figure 10.

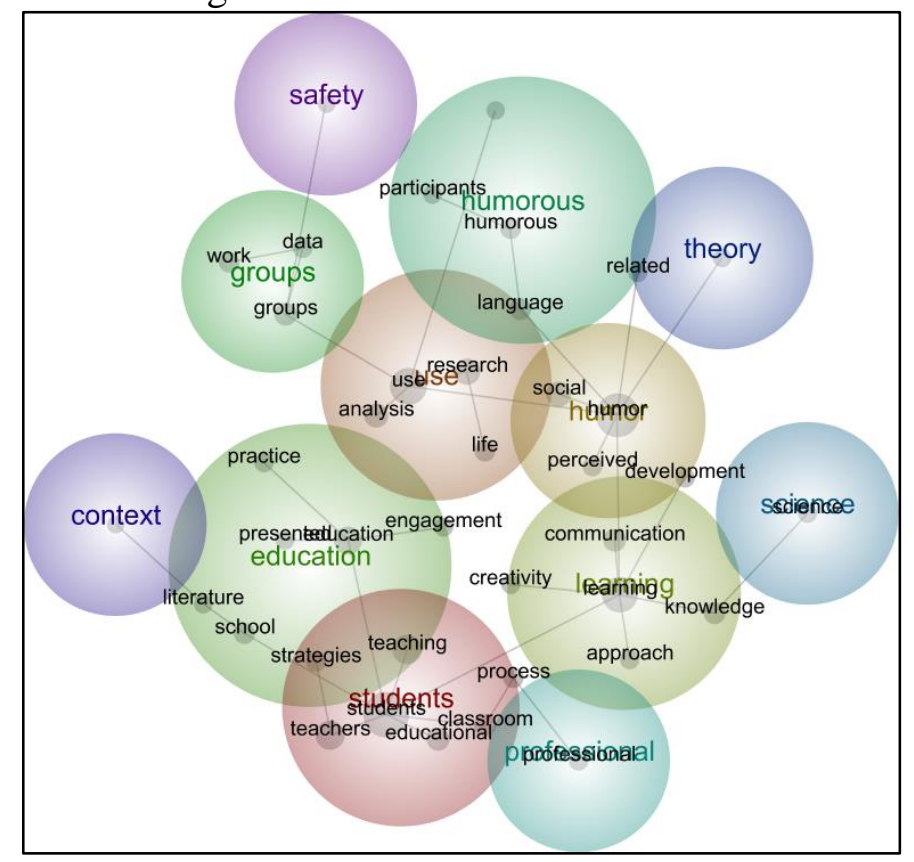

Figure 10. Overall concept map of the publications in the year 2015

The students theme with $100 \%$ level of relevance comprises of teachers, teaching, classroom, strategies and process concepts. This can be interpreted to mean that a humorous approach to the teaching process has been implemented in the classroom and is teacher dependent approach. In humor and learning themes with $\% 95$ and 60\% level of relevance respectively, social, development, communication, creativity, approach, perceived and knowledge concepts are shown as prominent because of the visible network of relationships between each other. Compared to previous years, science (11\%), context (\%7) and professional (12\%) concepts were not to be found as hit themes. This may indicate that humor is preferred in certain context in science education and professional development. Table 9 also shows ranked lists of the concepts associated with humor in 2015. 
Table 9. Ranked lists of the concepts associated with humor in 2015

\begin{tabular}{|c|c|c|c|c|c|}
\hline Concept & Relevance $(\%)$ & Bar Chart & Concept & Relevance $(\%)$ & Bar Chart \\
\hline students & 100 & & data & 15 & \\
\hline humor & 95 & & strategies & 12 & \\
\hline use & 65 & & professional & 12 & \\
\hline learning & 60 & & practice & 12 & \\
\hline teachers & 40 & & process & 11 & \\
\hline teaching & 38 & & approach & 11 & \\
\hline education & 37 & & development & 11 & \\
\hline research & 28 & & related & 11 & \\
\hline social & 27 & & science & 11 & \\
\hline groups & 25 & & participants & 11 & 匹 \\
\hline analysis & 22 & & presented & 11 & \\
\hline knowledge & 20 & & satisfaction & 11 & \\
\hline educational & 19 & & theory & 11 & \\
\hline language & 19 & & perceived & 10 & $\mathbf{L}$ \\
\hline work & 19 & & creativity & 10 & T \\
\hline communication & 18 & & engagement & 10 & 口 \\
\hline classroom & 17 & $\square$ & literature & 9 & प \\
\hline humorous & 16 & & safety & 9 & $\mathbf{\square}$ \\
\hline school & 15 & 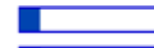 & context & 7 & ㅁ \\
\hline life & 15 & $\square$ & & & \\
\hline
\end{tabular}

As shown in Table 9, some concepts can be essential to properly understanding the use of humor in education as follows: social (27\% relevance), knowledge (20\% relevance), language (19\% relevance), communication (18\% relevance), classroom (17\%), school (15\%), professional $(12 \%)$, science $(11 \%)$, satisfaction $(11 \%)$, creativity $(10 \%)$, engagement $(10 \%)$ and safety (9\%) concepts. For the first time this year, the concepts of engagement and satisfaction belong to the terms used around humor.

\section{Concept Mapping for the Year 2016}

This year the concept map has more hit topics than in previous years. This diversity could be due to the increase in the number of articles analyzed this year. It includes 15 hit themes obtained from 138 publications. Figure 11 indicates the overall concept map of the publications in 2016. 


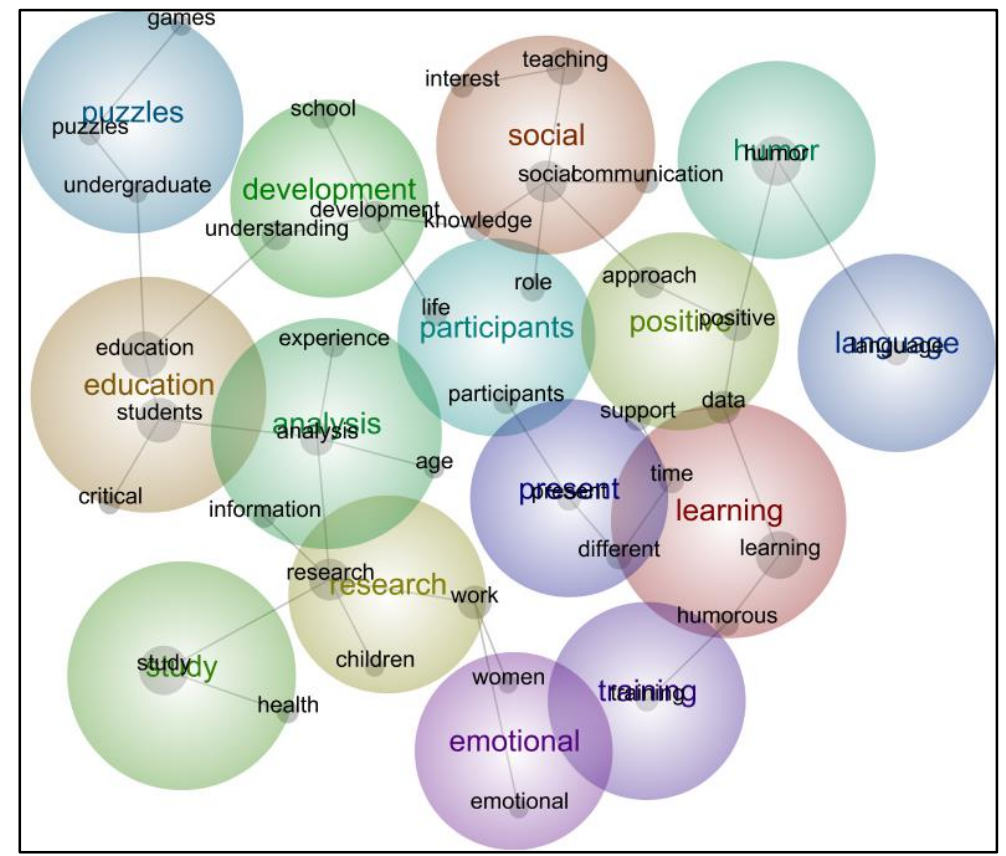

Figure 11. Overall concept map of the publications in 2016

Concepts of puzzles and emotional are emerging as hit theme for the first time this year. For puzzles (14\% relevance), there are undergraduate and games concepts with $11 \%$ relevance. This can highlight the use of humor in puzzle games for undergraduate students. One of the hit themes, emotional (8\%) concept includes women $(6 \%)$ concepts. This could show the humor studies in emotion as gender differences. For the first time since 2011, the language concept became a hit theme. But the level of relevance has dropped from $25 \%$ to $24 \%$ but it has appeared as a sub-concept in almost all years. Even if the level of relevance halved from 2014 to 2016, the concept of children (14\% to 8\%) still became the target group in educational humor studies. It is also interesting that the analysis by age appears as a concept in the concept map. Table 10 indicates all the ranked lists of the concepts associated with humor in 2016. 
Table 10. Ranked lists of the concepts associated with humor in 2016

\begin{tabular}{|c|c|c|c|c|c|}
\hline Concept & Relevance (\%) & Bar Chart & Concept & Relevance (\%) & Bar Chart \\
\hline humor & 100 & & time & 20 & \\
\hline study & 100 & & different & 20 & \\
\hline learning & 89 & 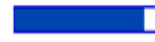 & communication & 19 & \\
\hline education & 84 & $\square$ & role & 18 & \\
\hline students & 77 & & participants & 18 & \\
\hline research & 65 & & experience & 17 & \\
\hline social & 62 & & training & 17 & \\
\hline teaching & 55 & & interest & 16 & \\
\hline work & 42 & & present & 16 & \\
\hline analysis & 42 & & health & 14 & \\
\hline data & 40 & & puzzles & 14 & \\
\hline positive & 37 & & information & 13 & \\
\hline development & 36 & & life & 13 & \\
\hline approach & 35 & & critical & 12 & \\
\hline understanding & 29 & & undergraduate & 11 & \\
\hline language & 24 & & games & 11 & \\
\hline knowledge & 22 & $\mathbf{L}$ & age & 9 & $\mathbf{I}$ \\
\hline support & 21 & & children & 8 & \\
\hline school & 21 & L & emotional & 8 & $\mathbf{L}$ \\
\hline humorous & 21 & L & women & 6 & \\
\hline
\end{tabular}

The concepts with relevance level that show the context in which humor is applied and the variables that humor is related are as follows: social (62\%), teaching (55\%), language (38\%), knowledge (22\%), support (21\%), school (21\%), communication (19\%), experience (17\%), training (17\%), and health (14\%). And the degree of relevance of social concepts is higher than in previous years.

\section{Concept Mapping for the Year 2017}

The year 2017 concept map produced from 134 publications in web of science database includes 14 hit themes as follows: study (100\% relevance), education (88\% relevance), learning (83\% relevance), research (67\% relevance), teaching (64\%), positive $(54 \%)$, analysis $(45 \%)$, social $(39 \%)$, work $(30 \%)$, understanding $(26 \%)$, role $(23 \%)$, knowledge (12\%), medical $(11 \%)$ and cognitive (10\%). The humorous concept (42\% relevance) emerged as a sub-concept, not a hit theme for this year, as the subject of humor may have been studied with more diverse concepts and may form part of the studies rather than the whole. Figure 12 shows the overall concept map of the publications in the year 2017. 


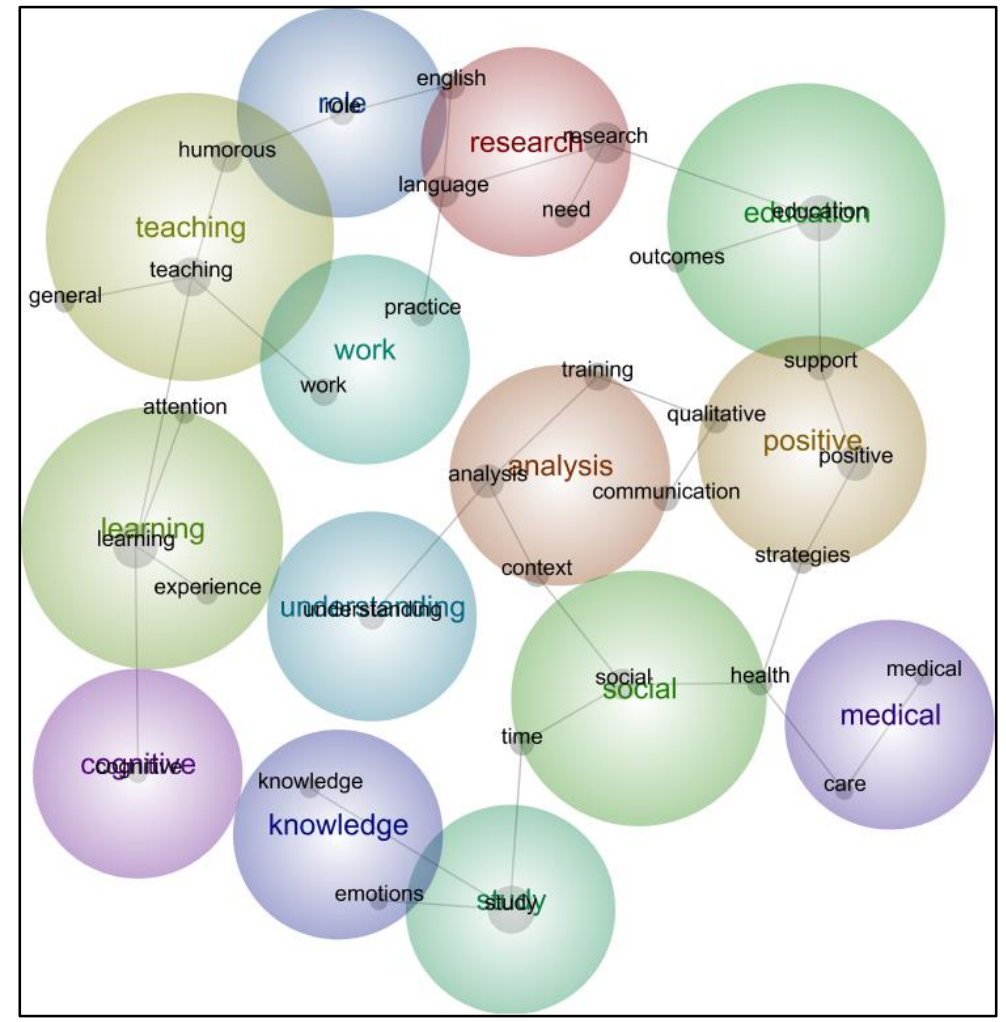

Figure 12. Overall concept map of the publications in the year 2017

As indicated in Figure 12, the concepts of cognitive and medical are a hit theme for the first time this year with $10 \%$ and $11 \%$ relevance rate respectively. Social concept, like 2016, is a hit theme (39\% relevance) this year. Table 11 indicates ranked lists of the concepts associated with humor in 2017.

Table 11. Ranked lists of the concepts associated with humor in 2017

\begin{tabular}{|c|c|c|c|c|c|}
\hline Concept & Relevance $(\%)$ & Bar Chart & Concept & Relevance $(\%)$ & Bar Chart \\
\hline study & 100 & & role & 23 & \\
\hline education & 88 & & time & 21 & \\
\hline learning & 83 & & qualitative & 20 & \\
\hline research & 67 & & context & 20 & \\
\hline teaching & 64 & & practice & 20 & \\
\hline positive & 54 & & strategies & 19 & \\
\hline analysis & 45 & & experience & 16 & \\
\hline humorous & 42 & & need & 15 & \\
\hline language & 39 & & general & 13 & \\
\hline social & 39 & & knowledge & 12 & \\
\hline english & 32 & & attention & 11 & \\
\hline work & 30 & & medical & 11 & \\
\hline support & 28 & & cognitive & 10 & \\
\hline training & 28 & & emotions & 9 & \\
\hline understanding & 26 & & care & 8 & \\
\hline health & 25 & & outcomes & 7 & \\
\hline communication & 23 & & & & \\
\hline
\end{tabular}

In Table 11, the most striking and meaningful concepts are the teaching (64\% relevance), language (39\% relevance), social (39\% relevance), English (32\%), support (28\%), training $(28 \%)$, health $(25 \%)$, communication $(23 \%)$, role $(23 \%)$, qualitative (20), context (20), practice (20), experience (16), knowledge (12\%), attention (11\%), medical (11\%), cognitive 
(11\%), emotions $(9 \%)$, and care (8\%). It is observed that humor studies in the field of health, qualitative research, and studies on cognitive and emotional dimensions of humor have increased according to the framework of the concept map. In addition, humor continues to be used in training and practice.

\section{Concept Mapping for the Year 2018}

The concept map of 2018 shows 11 hit themes from 149 publication related to humor in education as follows: humor (100\% relevance), students (54\% relevance), study (33\%), analysis (16\%), social (21\%), experience (17\%), teaching (20\%), data (9\%), classroom $(10 \%)$, practice $(8 \%)$, and individuals $(7 \%)$. These concepts mean that humor studies are carried out in the classroom as an instructional tool based on experiences in a social, individual, and practical framework.

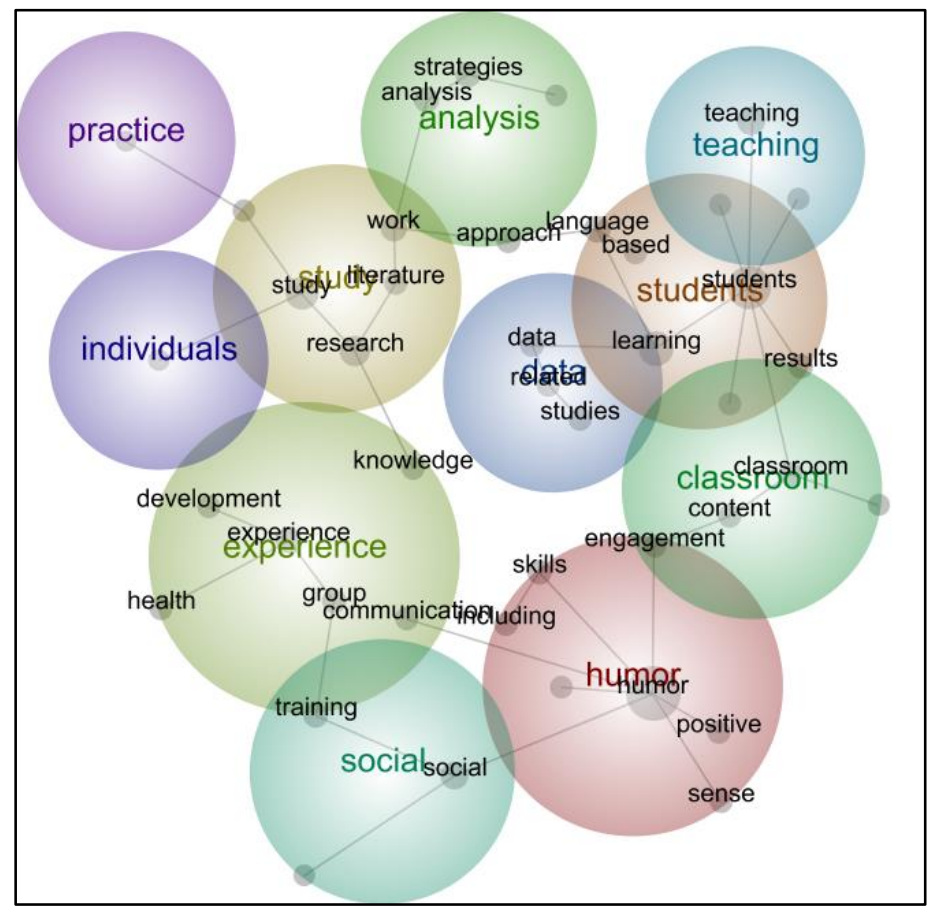

Figure 13. Overall concept map of the publications in the year 2018

Table 12 indicates the ranked lists of the concepts in the hit themes associated with humor in 2018. For example, content concept (10\% relevance) emerged this year. This can be a hint to use humorous content in the classroom. In addition, as in 2015, the engagement concept has a relevance of $8 \%$ and this did not exist in other previous years. this year the health concept (10\% relevance) appears again. Another notable concept, activities (7\% relevance), appears this year. This can show that activities are implemented in the learning process. 
Table 12. Ranked lists of the concepts associated with humor in 2018

\begin{tabular}{|c|c|c|c|c|c|}
\hline Concept & Relevance $(\%)$ & Bar Chart & Concept & Relevance $(\%)$ & Bar Chart \\
\hline humor & 100 & & health & 10 & Q \\
\hline students & 54 & & content & 10 & \\
\hline study & 33 & & literature & 10 & \\
\hline learning & 31 & & studies & 9 & ם \\
\hline research & 26 & & knowledge & 9 & + \\
\hline social & 21 & & data & 9 & 世 \\
\hline teaching & 20 & & sense & 9 & 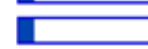 \\
\hline language & 17 & & including & 9 & 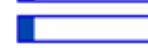 \\
\hline experience & 17 & & engagement & 8 & E \\
\hline analysis & 16 & & provide & 8 & $\pi$ \\
\hline work & 16 & & people & 8 & + \\
\hline strategies & 15 & & based & 8 & 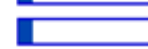 \\
\hline training & 14 & & higher & 8 & 世 \\
\hline results & 13 & & practice & 8 & 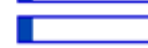 \\
\hline development & 12 & & related & 8 & 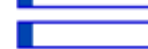 \\
\hline group & 12 & & different & 8 & \\
\hline communication & 11 & & role & 7 & 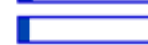 \\
\hline approach & 11 & & qualitative & 7 & T \\
\hline skills & 10 & & process & 7 & 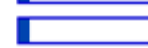 \\
\hline classroom & 10 & & individuals & 7 & 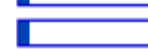 \\
\hline positive & 10 & 口 & activities & 7 & \\
\hline
\end{tabular}

Concept Mapping for the Year 2019

The 13 hit themes consist of 153 publications that were produced in 2019. The concept map consists of the following themes: humor (100\% relevance), study (100\% relevance), learning (99\% relevance), students (96\% relevance), education ( $82 \%$ relevance), research ( $71 \%$ relevance), undergraduate $(61 \%)$, results $(50 \%)$, communication $(35 \%)$, language (44\%), chemistry (30\%), health (30\%), and different $(28 \%)$. In these hit themes, chemistry and health concepts for the area of humor are particularly important. Compared to previous years, language, undergraduate and communication concepts have a higher relevance rate and appears as hits. 


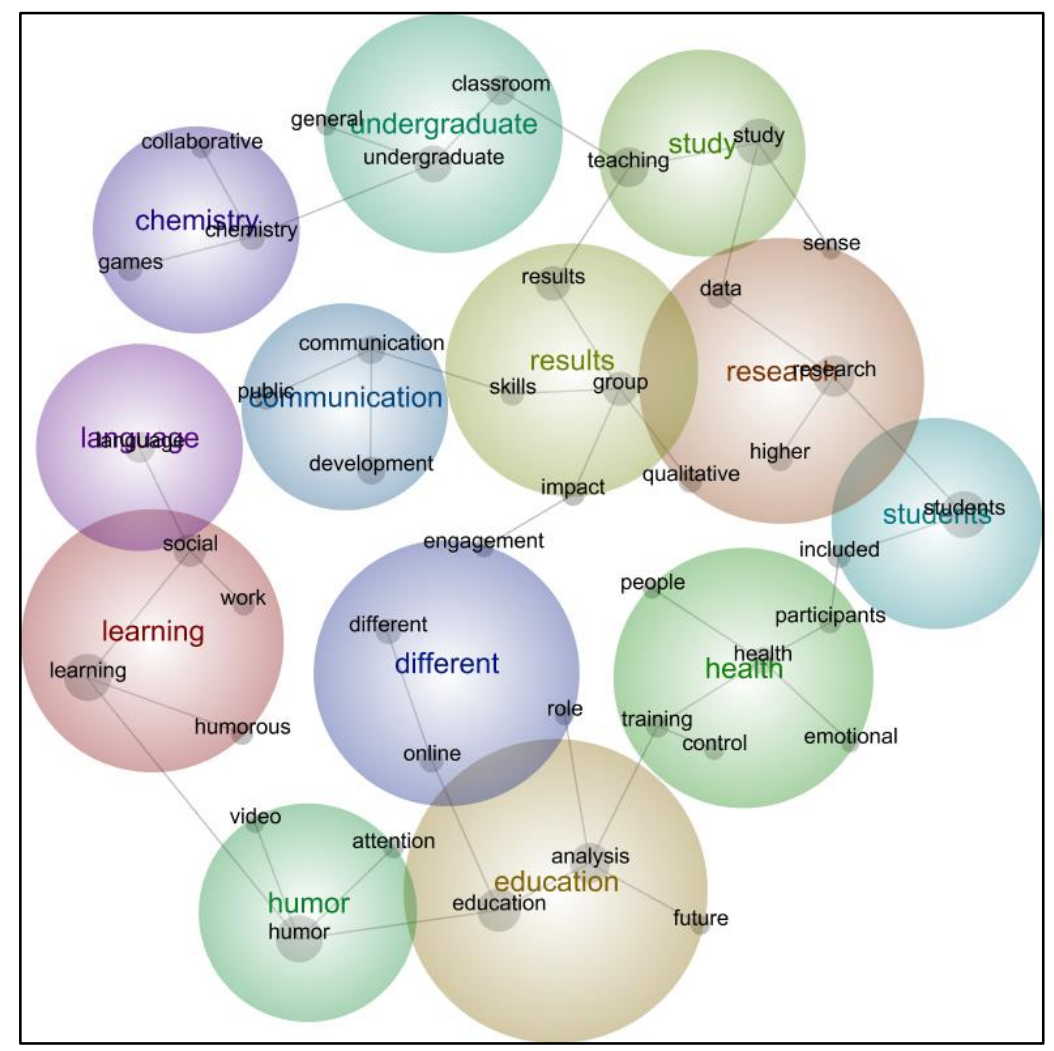

Figure 14. Overall concept map of the publications in the year 2019

Table 13 indicates the ranked lists of the concepts associated with humor in 2019. The striking concepts are as follows: teaching (68\% relevance), undergraduate (61\% relevance), social (48\% relevance), language (44\%), classroom (41\%), communication (35\%), health $(30 \%)$, chemistry $(30 \%)$, games $(27 \%)$, online $(25 \%)$, qualitative $(22 \%)$, skills $(22 \%)$, training (20\%), attention (17\%), collaborative (15\%), video (12\%), engagement (11\%) and emotional $(10 \%)$. In this concept list, online, games, collaborative and video concepts can be portrayed as important as humor can be used in games and videos. And it prefers collaborative and online learning as an educational power. 
Table 13. Ranked lists of the concepts associated with humor in 2019

\begin{tabular}{|c|c|c|c|c|c|}
\hline Concept & Relevance $(\%)$ & Bar Chart & Concept & $\begin{array}{l}\text { Relevance } \\
(\%)\end{array}$ & Bar Chart \\
\hline humor & 100 & & online & 25 & \\
\hline study & 100 & & qualitative & 22 & \\
\hline learning & 99 & & skills & 22 & \\
\hline students & 96 & & public & 21 & \\
\hline education & 82 & & humorous & 21 & \\
\hline research & 71 & & impact & 20 & \\
\hline analysis & 70 & L & training & 20 & \\
\hline teaching & 68 & & included & 20 & \\
\hline undergraduate & 61 & & work & 19 & \\
\hline results & 50 & & participants & 19 & \\
\hline group & 48 & & attention & 17 & \\
\hline social & 48 & & collaborative & 15 & \\
\hline language & 44 & & future & 14 & \\
\hline classroom & 41 & & general & 14 & \\
\hline communication & 35 & & sense & 14 & \\
\hline development & 32 & & control & 13 & \\
\hline data & 31 & & role & 13 & \\
\hline health & 30 & & video & 12 & \\
\hline chemistry & 30 & & people & 11 & \\
\hline different & 28 & & engagement & 11 & 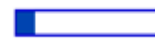 \\
\hline games & 27 & & emotional & 10 & \\
\hline higher & 26 & 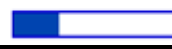 & & & \\
\hline
\end{tabular}

\section{Conclusion and Discussion}

The titles, abstracts, and keywords of the humor studies in education between 2010 and 2019 were converted into concept maps using the text mining method. As a result of the study, humor was studied in terms of various variables in different educational fields. In addition, the reflections of humor in education base on technological developments and the target groups applied were also revealed. As the concept map of humor studies in the last decade of education is drawn, "language" concept come to the fore each year. Considering the other concepts related to the "language" concept, humor is effectively implemented and continued in language education. Andarab (2019) claims that appropriate humor has the potential to facilitate the language learning process. This may be because the humorous elements help to remind vocabulary. It is also noteworthy that humor was preferred in science education in a few years' time. Then a general case, the science class, reached a special situation and appeared as a hit in chemistry class in 2019. Students often find science lessons difficult and boring. They also have difficulty memorizing subjects and rules in chemistry class (Yenikalayc1 et al., 2019) so humor can be a remedy for learning process of science education. It is also remarkable that humor is practiced almost in the field of health education and has recently been a hit theme. The use of humor by health education professionals can be important as the fact that health care professionals post humorous videos on social media shows that it can be essential to alleviating pandemic process. Educating people to use humor in a healthy way can have positively health effects (Ruch \& McGhee, 2014). Improving the sense of humor of people who constantly interacting with someone can be important to professional success.

The social dimension of humor emerged from the concept maps in the educational processes. In recent years it has been notable that the "social" concept has been a hit theme. Using humor effectively is a social skill, initiates social interaction and provides social competence (Yip \& Martin, 2006). From a pedagogical point of view, humor can support the social 
dimension of learning. Humor also plays an indispensable element in communicative aspect of education as well as in the social aspect of humor. Humor strengthens communication between teacher and student, but also promotes learning (Sidelinger \& Tatum, 2019). It can therefore be concluded that humor is often used as a communication strategy by teachers in learning settings.

Emotions have an extremely important place in educational processes. Emotions are a psychological process that includes emotional, cognitive, physiological, and motivational components (Shuman \& Scherer, 2014). Emotions are also crucial for learning and engagement (Linnenbrink-Garcia et al., 2016). The fact that humor has a structure that can lead to a preference in learning processes. Humor creates positive emotions in the individual and thus has the potential to increase engagement for the course (Edwards 2018). While the emotional dimension of humor in education is the subject of the studies, it is noteworthy that in recent years, the cognitive dimension has begun to be explored, albeit a little.

With the development and proliferation of technology, reflections on humor in education have become inevitable. Practitioners and teachers may need new methods and techniques in the process of learning with technology. As a result of this need, it was concluded that humor is an effective method, as it is noteworthy in the humor studies that the concepts of "videos, games, puzzles, online, and media" are highly relevant. Humor that is used in the course material (video, presentation, visuals etc.) and relates to the subject provides sustainable attention and can create a relaxing and productive learning environment (Savage, Lujan et al., 2017). It is also remarkable that humor is used in online learning environments. In a study by Berge (2017), it was found that the use of humor in online discussions can increase social interaction and that this situation can positively influence active participation. In addition, Huang et al. (2017) implemented humorous visuals in course contents for reward purposes and concluded that students' learning efforts increased, and they wanted to spend more time in with the content by developing a positive perspective on the course. The integration of technology and humor into learning processes, especially online learning processes, may become more common with the spread of distance learning.

The research variables examined in connection with humor in education also were also made clear by the concept maps. Dependent variables such as motivation, attention, skill, creativity, engagement, and interest have been studied in particular in humor studies in education over the past decade. This result could explain that educational humor influences these variables. Humor has a potential that can capture and maintain the student's attention and motivation (Shatz \& Coil, 2008). Humor can create a learning environment that strengthens relationship between people, reduces social distance, and is not fearful (Graham, 1995) so that it can increase students' interest and engagement in the classroom. In addition, the fact that the concepts of "classroom and school" emerged as a concept over many years indicates that humor is often preferred in face-to-face environments and that the concept of "teaching" is also preferred by teachers in the classroom. Moreover, humor is also used in training-based educational processes. Although applied studies of humor in education are quite limited, most of them have been conducted in personal learning settings, and these studies have focused more on teacher humor use (Bieg et al., 2010; Maclev \& Karlin, 2016). Since children are preferred as the target audience in educational humor studies in the first few years, it has been shown that humor studies have begun to be used in undergraduate studies in recent years. This may be because humor is a need for people of all ages. It also reveals that qualitative studies have been carried out recently. It may focus on qualitative research to examine in depth the effect of humor in the learning process. Furthermore, when comparing 2010 and 2019, it is 
noticeable that concepts related to online education, science, collaborative learning and technology in humor studies have spread in recent years.

This article is limited to educational humor studies over the past few decades and only preferred the Web of Science (WoS) database. Only the titles, abstracts and key words of the studies are included in the text analytical process. Future research can focus on different aspects of humor use in education by using a different database, search queries, and text analysis tools. In addition, researchers can determine trends in humor studies in education by analyzing the conclusion section of studies for text mining.

\section{Conflict of interest}

They have no conflict of interest

\section{References}

Andarab, M. S. (2019). The Effect of Humor-Integrated Pictures Using Quizlet on Vocabulary Learning of EFL Learners. Journal of Curriculum and Teaching, 8(2), 2431. doi: $10.5430 /$ jct.v8n2p24

Archambault, É., Vignola-Gagné, É., Côté, G., Larivi? re, V., \& Gingrasb, Y. (2006). Benchmarking scientific output in the social sciences and humanities: The limits of existing databases. Scientometrics, 68(3), 329-342. doi:10.1007/s11192-006-0115-z

Banas, J. A., Dunbar, N., Rodriguez, D., \& Liu, S. J. (2011). A review of humor in educational settings: Four decades of research. Communication Education, 60(1), 115144. doi:10.1080/03634523.2010.496867

Berge, M. (2017). The role of humor in learning physics: A study of undergraduate students. Research in Science Education, 47(2), 427-450. doi: 10.1007/s11165-015-9508-4

Berk, R. A. (1996). Student ratings of 10 strategies for using humor in college teaching. Journal on Excellence in College Teaching, 7(3), 71-92.

Bieg, S., Grassinger, R., \& Dresel, M. (2019). Teacher humor: Longitudinal effects on students' emotions. European Journal of Psychology of Education, 34(3), 517-534. doi:10.1007/s10212-018-0402-0

Carrel, A. (2008). Historical views of humor. In V. Raskin (eds.), The primer of humor research, 303-332. Berlin: Walter de Gruyter.

Chang, H. J., Wang, C. Y., Chen, H. C., \& Chang, K. E. (2014). The analysis of elementary and high school students' natural and humorous responses patterns in coping with embarrassing situations. Humor, 27(2), 325-347. doi:10.1515/humor-2013-0059

de la Rosa, P. S. (2005). Toward a more reflective teaching practice: Revisiting excellence in teaching. Asia Pacific Education Review, 6(2), 170-178. doi:10.1007/BF03026785

Delgado, M., Martín-Bautista, M. J., Sánchez, D., \& Vila, M. A. (2000). Mining text data: special features and patterns. In D.J. Hand, N.M. Adams \& R.J. Bolton, Pattern Detection and Discovery (140-153). Berlin: Springer.

Edwards, E. (2018). Exploring the use of humor in medical education in the GP small group setting. Education for Primary Care, 29(6), 383-384. doi:10.1080/14739879.2018.1509677

Garner, R. L. (2006). Humor in pedagogy: How ha-ha can lead to aha!., College Teaching, 54(1), 177-180. doi:10.3200/CTCH.54.1.177-180

Graham, E. E. (1995). The involvement of sense of humor in the development of social relationships. Communication Reports, $8(2), \quad 158-169$. doi:10.1080/08934219509367622 
Grech, M. R., Horberry, T., \& Smith, A. (2002, September). Human error in maritime operations: Analyses of accident reports using the Leximancer tool. In Proceedings of the human factors and ergonomics society annual meeting, 46(19), 1718-1721. Sage CA: Los Angeles, CA: Sage Publications.

Guo, H. \& Wang, H. (2017). Visualizing the knowledge domain of humor processing: a scientometric review. Chinese Journal of Applied Lingusitics, 40(2), 192-207. doi:10.1515/cjal-2017-0012

Hellman, S. V. (2007). Humor in the classroom: Stu's seven simple steps to success. College Teaching, 55(1), 37-39. doi:10.3200/CTCH.55.1.37-39

Hyndman, B., \& Pill, S. (2018). What's in a concept? A Leximancer text mining analysis of physical literacy across the international literature. European Physical Education Review, 24(3), 292-313. doi:10.1177/1356336X17690312

Huang, Y. M., Liu, M. C., Lai, C. H., \& Liu, C. J. (2017). Using humorous images to lighten the learning experience through questioning in class. British Journal of Educational Technology, 48(3), 878-896. doi:10.1111/bjet.12459

Khan, A., \& Ghosh, S. K. (2020). Student performance analysis and prediction in classroom learning: A review of educational data mining studies. Education and Information Technologies, 26(1), 205-240. doi: 10.1007/s10639-020-10230-3

Lefcourt, H. M. (2001). Humor: The psychology of living buoyantly. New York: Kluwer Academic

Lei, S. A., Cohen, J. L., \& Russler, K. M. (2010). Humor on learning in the college classroom: Evaluating benefits and drawbacks from instructors' perspectives. Journal of Instructional Psychology, 37(4), 326-332. Retrieved from https://go.gale.com/ps/i.do?id=GALE\%7CA249957357\&sid=googleScholar\&v=2.1\&i $\mathrm{t}=\mathrm{r} \&$ linkaccess $=\mathrm{abs} \& \mathrm{issn}=00941956 \& \mathrm{p}=\mathrm{HRCA} \& \mathrm{sw}=\mathrm{w} \&$ userGroupName $=$ anon $\% 7 \mathrm{E}$ dc4fe79d

Linnenbrink-Garcia, L., Patall, E. A., \& Pekrun, R. (2016). Adaptive motivation and emotion in education: Research and principles for instructional design. Policy Insights from the Behavioral and Brain Sciences, 3(2), 228-236. doi:10.1177/2372732216644450

Machlev, M., \& Karlin, N. J. (2016). Understanding the relationship between different types of instructional humor and student learning. SAGE Open, 6(3), 1-9. doi:10.1177/2158244016670200

Martin, R. A., \& Ford, T. (2018). The psychology of humor: An integrative approach. Oxford: Elsevier Academic Press.

Martin, R. A. (2004). Sense of humor and physical health: Theoretical issues, recent findings, and future directions. Humor, 17, 1-20. doi:10.1515/humr.2004.005

Matarazzo, K. L., Durik, A. M., \& Delaney, M. L. (2010). The effect of humorous instructional materials on interest in a math task. Motivation and emotion, 34(3), 293305. doi:10.1007/s11031-010-9178-5

Neff, P., \& Rucynski, J. (2017). Japanese perceptions of humor in the English language classroom. Humor, 30(3), 279-301. doi:10.1515/humor-2016-0066

Nunez-Mir, G. C., Iannone, B. V., Curtis, K., \& Fei, S. (2015). Evaluating the evolution of forest restoration research in a changing world: a "big literature" review. New Forests, 46(5-6), 669-682. doi:10.1007/s11056-015-9503-7

Nunez-Mir, Gabriela C., Iannone, Basil V., Pijanowski, Bryan C., Kong, Ningning \& Songlin Fei. 2016. Automated content analysis: addressing the big literature challenge in ecology and evolution. Methods in Ecology and Evolution, 7(11), 1262-1272. doi:10.1007/s11056-015-9503-7 
Pekrun, R. \& Perry, R. P. (2014). Control-value theory of achievement emotions. In R. Pekrun \& L. Linnenbrink-Garcia (eds.), International handbook of emotions in education, 120-141, New York: Taylor \& Francis.

Poirier, T. I., \& Wilhelm, M. (2014). Use of humor to enhance learning: bull's eye or off the mark. American journal of pharmaceutical education, 78(2). doi:10.5688/ajpe78227

Reigeluth, C. M. (2013). Instructional design theories and models: An overview of their current status. Routledge.

Ruch, W., \& McGhee, P. E. (2014). Humor intervention programs. In A. C. Parks \& S. M. Schueller (Eds.), The Wiley Blackwell handbook of positive psychological interventions, 179-193. Wiley Blackwell. doi:10.1002/9781118315927.ch10

Ruch, W. \& Hofmann, J. (2017). Fostering humor. In C. Proctor (eds.). Positive psychology interventions in practice, 65-80. CH: Springer.

Rule, A. C., \& Auge, J. (2005). Using humorous cartoons to teach mineral and rock concepts in sixth grade science class. Journal of Geoscience Education, 53(5), 548-558. doi:10.5408/1089-9995-53.5.548

Sahin, A. (2018). Humor in Educational Institutions as an Administrative and Educational Tool. Ankara: Ani Press.

Savage, B. M., Lujan, H. L., Thipparthi, R. R., \& DiCarlo, S. E. (2017). Humor, laughter, learning, and health! A brief review. Advances in Physiology Education, 41(3), 341347. doi:10.1152/advan.00030.2017

Shatz, M. A., \& Coil, S. R. (2008). Regional campus teaching ain'ta joke but humor can make it more effective. Association for University Regional Campuses of Ohio, 14, 105-117.

Sidelinger, R. J., \& Tatum, N. T. (2019). Instructor humor as a moderator of instructors' inappropriate conversations and instructional dissent. College Teaching, 67(2), 120129. doi:10.1080/87567555.2018.1564233

Shuman, V., \& Scherer, K. R. (2014). Concepts and structures of emotions. In R. Pekrun \& L. Linnenbrink-Garcia (eds.), International handbook of emotions in education,13-35. New York: Taylor \& Francis.

Tsukawaki, R., Imura, T., Kojima, N., Furukawa, Y., \& Ito, K. (2020). The correlation between teachers' humor and class climate: A study targeting primary and secondary school students. Humor, 1-17. doi:10.1515/humor-2019-0021

Yenikalaycı, N., Çelikler, D., \& Aksan, Z. (2019). Ion Hunters: Playing a Game to Practice Identifying Anions and Cations and Writing Their Names and Formulas. Journal of Chemical Education, 96(11), 2532-2534. doi:10.1021/acs.jchemed.8b00732

Yip, J. A., \& Martin, R. A. (2006). Sense of humor, emotional intelligence, and social competence. Journal of research in personality, 40(6), 1202-1208. doi:10.1016/j.jrp.2005.08.005 